\title{
Descolonizando nossos feminismos
}

\author{
Más allá del feminismo: caminos \\ para andar. \\ MILLÁN, Márgara (Org.). \\ México: Red de Feminismos Descoloniales, \\ 2014, 328p.
}

O livro Más allá del feminismo: caminos para andar está organizado em 14 capítulos, além de uma introdução e de uma apresentação da Red de Feminismos Descoloniales. A publicação foi originalmente concebida como o resultado dos trabalhos e dos diálogos coletivos produzidos pela referida rede, em 2008, no México. O projeto inicial da rede passou por várias fases até chegar, a partir de 2012, à configuração que hoje se constitui. Conforme a organizadora do volume, a antropóloga e feminista Márgara Millán, a proposta inicial de um projeto dedicado ao feminismo descolonial partiu da iniciativa de Sylvia Marcos, uma das principais impulsionadoras da Red, o qual incluía uma articulação entre pesquisadoras do México e da Bolívia; no entanto, esse projeto inicial não se consolidou. Desse modo, Márgara Millán, em parceria com outras pesquisadoras feministas, tem continuado o projeto no México.

A Red de Feminismos Descoloniales congrega diversas pesquisadoras, oriundas de diferentes campos disciplinares e localidades geográficas, que compartilham $\circ$ interesse comum por um feminismo otro. Este feminismo otro, reivindicado por essas estudiosas, tem sido definido como sendo um feminismo descolonial, o qual se organiza e se orienta sob a influência da proposta zapatista, a saber, de "otro mundo es posible" (Márgara MILLÁN, 2014, p. 9). Para elas, o zapatismo mexicano possui relevância política e epistemológica, uma vez que, ao interpelar o projeto que institui o feminismo, incitao a produzir uma crítica sobre si mesmo e, ao mesmo tempo, agencia um processo de descolonização intelectual.

Isso posto, a crítica epistemológica descolonial, como parte desse feminismo otro funda-se, sobretudo, no reconhecimento dos aportes proporcionados pelas cosmovisões mesoamericanas e ameríndias, assim como pelas lutas camponesas e populares, além dos outros sujeitos políticos denominados subalternos. Desse modo, ao articular essas diversas lutas feministas à crítica epistemológica descolonial, as pesquisadoras da Red participam de distintos espaços de discussões com o intuito de evidenciar as práticas e os discursos acadêmicos que acomodam a colonialidade do conhecimento como um discurso legítimo, o qual não permitiria aberturas para a experimentação de pensamentos pretensamente não convencionais. Nesse sentido, dos 14 capítulos do livro, 11 partem de um diálogo com o mundo indígena - os quais versam, em linhas gerais, sobre o caminho descolonial do feminismo, as ontologias da diversidade, os essencialismos estratégicos e os discursos de descolonização, o feminismo moderno e o significado de suas políticas, os feminismos e a descolonização epistêmica, os alcances ontológicos dos feminismos indígenas, os saberes femininos no ambiente comunitário do campesinato, a práxis feminista sob a perspectiva do zapatismo, a homossexualidade nos povos indígenas, entre outras questões.

Com a finalidade de construir uma prática descolonizadora efetivamente eficaz, as autoras não pretendem instituir uma teoria da descolonização e da crítica epistemológica do feminismo, mas intencionam explorar o campo de possibilidades que emergem das práticas que, nas suas análises, podem ser designadas descoloniais - a partir de experiências múltiplas, diversas e muitas vezes conflitantes. Nesse sentido, 
ao colocar em perspectiva teorias tecidas em articulação com as suas práticas, as autoras privilegiam o uso da palavra descolonial , ao invés de decolonial, com o intuito de se diferenciarem da teoria da decolonialidade, ainda que diversas pesquisadoras da Red façam uso de conceitos centrais do pensamento decolonial.

A permanente abertura para 0 diálogo com outras análises já instituídas, buscando encontrar as junções e as disjunções com as práticas descolonizadoras, seria, precisamente, o que diferencia o feminismo descolonial. O descolonial poderia ser definido mais como um pensamento em fluxo contínuo que uma teoria fechada, ou, ainda, um pensamento concreto. Com isso, pretende-se elaborar um pensamento que abra o caminho para o novo sem, todavia, recusar o diálogo com os conceitos e teorias em vigor, caminho que deve ser construído desde as localidades e as temporalidades das lutas e pesquisas feministas, nas quais cada pesquisadora, cada uma à sua maneira, posiciona-se.

Para as autoras do livro, uma prática descolonizadora não implica apenas reconhecer o diálogo com a estrutura de pensamento de outros horizontes epistemológicos, mas, principalmente, elaborar um pensamento próprio, calcado, nomeadamente, em uma tradição intelectual feminista desde "abajo y a la izquierda" (MILLÁN, 2014, p. 11). No entanto, mais do que construir uma crítica feminista fazendo uso das análises e das críticas epistemológicas tradicionalmente instituídas, uma prática descolonizadora, cuja finalidade seria instituir-se como epistemologia feminista, deve ter a pretensão de descentrar certezas e ampliar o pensamento para novas indagações, de modo a aprofundar o próprio horizonte feminista e suas propostas metodológicas. Sob esse prisma epistemológico, as autoras vão tecendo inspiradoras análises e insinuando abertos e incompletos caminhos a serem trilhados, os quais não devem ser adotados como uma autoridade analítica ou conceitual por decreto, ou, ainda, como uma resolução pragmática, pois não se tratam de perspectivas monótonas nos seus alcances teóricos, tampouco são modelos encerrados em si mesmos.

Nesse sentido, ainda que uma leitura menos polida possa nos conduzir, apressadamente, a perceber os capítulos como dissimilares, uma leitura um pouco mais refinada prontamente nos levará a perceber que os capítulos, cuidadosamente, dialogam entre si. No entanto, esse diálogo não implica ausência de discordâncias, uma vez que os capítulos foram tecidos considerando o vigor das discussões coletivas agenciadas pela Red. Apesar de compartilharem horizontes comuns, as autoras não têm por finalidade instituir uma nova teoria, ou, ainda, concretizar um único modo de pensar, mas pretendem apenas reconhecer os caminhos sinuosos e muitas vezes conflitantes do pensar. Nessa perspectiva, o volume pretende romper com a acomodação da colonialidade do conhecimento e provocar uma certa desordem no pensamento feminista, a partir dos contrastes entre influências teóricas e de tensões entre posições, na mesma medida em que nos convida a alargar o nosso ato de mirar feminista, com cada vez mais indagações e cada vez menos certezas.

As reflexões desencadeadas nos capítulos instigaram a estabelecer uma ponte entre as discussões que vigorosamente aguçam as críticas epistemológicas feministas no México (MILLÁN, 2011) e os inspiradores debates feministas que recentemente prosperam no Brasil (Fabiano de Souza GONTIJO, 2013). Refiro-me aqui, mais precisamente, aos estudos feministas que têm como horizontes privilegiados de análise a complexidade que marca a experiência da diversidade sexual e de gênero nas zonas rurais brasileiras, bem como os contextos interioranos, caboclos e ribeirinhos e as situações etnicamente diferenciadas, indígenas e quilombolas, principalmente na Amazônia (GONTIJO, 2015a).

Esses estudos assinalam, em linhas muito gerais, para a realidade complexa e diversificada que modula as dinâmicas interações produzidas nos mundos rural e interiorano amazônicos e nos contextos indígenas e etnicamente diferenciados. Desse modo, esses estudos colocam em relevo os desencaixes ou as lacunas, assim como as ausências e os possíveis silenciamentos que vigoram, por um lado, nos estudos sobre etnicidade e sobre povos e comunidades tradicionais, e, por outro, nos estudos sobre ruralidade e sobre gênero e sexualidade. A partir de uma perspectiva desconstrutivista, também evidenciam a relevância epistemológica que as pesquisas sobre as experiências da diversidade sexual e de gênero nos contextos interioranos e nas situações etnicamente diferenciadas oferecem para os feminismos brasileiros, uma vez que, particularmente, nesses campos de conhecimento, tais temáticas vêm disputando discursos e produzindo tensões.

Ainda que permaneçam (quase) inexploradas (ou abordadas tangencialmente) 
no âmbito das Ciências Humanas (Pedro Rosas MAGRINI, 2015) e, em particular, na Antropologia (Fabiano de Souza GONTIJO; Igor ERICK, 2015b), essas temáticas têm reavivado os estudos de gênero e sexualidade, descentralizado os horizontes epistemológicos dos feminismos brasileiros, visto que aprofundam as críticas feministas sobre si mesmas, na mesma medida em que as encorajam a descolonizar os seus próprios pensamentos. Desse modo, essas temáticas também provocam dúvidas quanto às análises canônicas produzidas até o momento e convidam os feminismos brasileiros a construírem novos pensamentos sem, contudo constituírem-se em uma recusa às tradições intelectuais feministas consolidadas no país.

O livro, portanto, nos conduz a pensar as aproximações epistemológicas entre feminismo latino-americano descolonial e estudos póscoloniais latino-americanos, assim como as imbricações entre teorias pós-coloniais e leituras antropológicas sobre feminismos, gênero e sexualidade no Brasil.

\section{Referências}

GONTIJO, Fabiano de Souza. "Diversidade Sexual e de Gênero no Mundo Rural Brasileiro: esboço de reflexões preliminares". Revista FSA, Teresina, v. 10, n. 2 , p. $84-100$, abr./jun. 2013.

. "Sexualidade e ruralidade no Brasil: o que os estudos rurais e os estudos de gênero e sexualidade (não) dizem sobre essa relação?"
Vivência - Revista de Antropologia, Natal, $n$. 45, p. 145-158, 2015a.

GONTIJO, Fabiano de Souza; ERICK, Igor. "Diversidade Sexual e de Gênero, Ruralidade, Interioridade e Etnicidade no Brasil: Ausências, Silenciamentos e... Exortações". ACENO - Revista de Antropologia do CentroOeste, v. 2, n. 4, p. 24-40, ago./dez. 2015b. MAGRINI, Pedro Rosas. Produção acadêmica sobre o MST: perspectivas, tendências e ausências sobre gênero, sexualidade, raça e suas interseccionalidades. 2015. Tese (Doutorado Interdisciplinar em Ciências Humanas) - Programa de Pós-Graduação Interdisciplinar em Ciências Humanas, Centro de Filosofia e Ciências Humanas da Universidade Federal de Santa Catarina, Florianópolis.

MILLÁN, Márgara. "Feminismos, postcolonialidad, descolonización: ¿del centro a los Márgenes?". Andamios, vol. 8 n. 17, México, p. 11-36, set./dez. 2011.

(Org.). Más allá del feminismo: caminos para andar. México: Red de Feminismos Descoloniales, 2014.

[Recebida em 10/04/2016 e aceita para publicação em 25/04/2016]

Jainara Gomes de Oliveira

Universidade Federal de Santa Catarina, Florianópolis, Santa Catarina, Brasil 